\title{
Desempenho e qualidade dos ovos de poedeiras comerciais no segundo ciclo de produção consumindo gérmen integral de milho
}

\author{
Alexandre Barbosa de Brito ${ }^{1}$, José Henrique Stringhini ${ }^{2,3}$, Suzany Aparecida Gomes Xavier ${ }^{1}$, \\ Marcos Barcellos Café2,3, Nadja Susana Mogyca Leandro 2,3
}

\author{
1 Poli-Nutri Alimentos, Rua Américo Vespúcio, no 99, Osasco (SP, Brasil). \\ ${ }^{2}$ Departamento de Produção Animal, Escola de Veterinária, Universidade Federal de Goiás, Goiânia (GO). \\ ${ }^{3}$ Bolsista do CNPq.
}

RESUMO - O experimento foi conduzido com o objetivo de avaliar o desempenho e a qualidade dos ovos de poedeiras comerciais no segundo ciclo de produção consumindo gérmen integral de milho em substituição ao milho da dieta. O procedimento de muda forçada foi adotado em 250 aves Lohmann LSL durante a 66a e a 74a semanas de idade. $\mathrm{Na} 75^{a}$ semana de idade, 192 aves foram uniformizadas pelo peso. O período experimental correspondeu ao intervalo da $78^{\underline{a}}$ a $90^{\underline{a}}$ semana de idade das aves. Foram avaliados quatro níveis de substituição do milho pelo gérmen integral de milho na dieta $(0,25,50$ e 75\%). As variáveis avaliadas foram os parâmetros de desempenho e qualidade interna e externa de ovos. O delineamento utilizado foi o inteiramente casualizado e os dados foram analisados utilizando-se regressão polinomial. De acordo com os resultados obtidos, a utilização do gérmen integral de milho é recomendável até o nível de $25 \%$ de substituição ao milho, o que significa inclusão de $16 \%$ de gérmen integral de milho em dietas para poedeiras comerciais no segundo ciclo de produção.

Palavras-chave: consumo de ração, porcentagem de postura, qualidade de casca, qualidade interna

\section{Performance and egg quality of laying hens after molting (78 to 90 weeks of age) fed corn germ meal}

\begin{abstract}
This experiment was carried to evaluate the performance and egg quality of laying hens in the second production cycle consuming whole corn germ in substitution of corn in the diet. The forced molting procedure of 250 Lohmann LSL laying hens was accomplished in the $66^{\text {th }}$ to $74^{\text {th }}$ weeks of age. In $75^{\text {th }}$ week of age, 192 birds were standardized by weight. The experimental period coreresponded to the interval between the $78^{\text {th }}$ and $90^{\text {th }}$ weeks of age of the hens. Four levels were evaluated of replacing corn with corn germ meal in the diets (0, 25, 50 and 75\%). The variables assessed were internal and external egg quality and performance. A randomized complete design was used and statistical analyses were performed using polynomial regression analysis. The level recommended was up to $25 \%$ of substitution for corn, that means $16 \%$ corn germ meal included in diets for molted hens in the second cycle production.
\end{abstract}

Key Words: egg internal quality, egg production percentage, eggshell quality, feed intake

\section{Introdução}

A muda é um processo natural que acontece nas aves para renovar sua plumagem antes das épocas frias ou da migração anual. Nas aves domésticas selecionadas para alta produção de ovos, a muda de penas ocorre após longo período de produção e dura cerca de quatro meses. É possível, contudo, acelerar esse processo com um programa destinado à indução da muda, ou seja, muda forçada. Muitos métodos de muda forçada têm sido estudados e, de acordo com Garcia (2004), podem ser reunidos em três grupos: o primeiro refere-se ao uso de fármacos (ex.: acetato de clormadiona); o segundo, ao uso de programas nutricionais com mudança na concentração de determinados nutrientes na dieta importantes para produção de ovos (ex.: cálcio, fósforo); e, por fim, às alterações de manejo, com redução no fornecimento de ração, e pela redução do fotoperíodo por restrição da iluminação artificial. 
Em razão do período de jejum prolongado, a dieta no segundo ciclo de produção deve propiciar o restabelecimento do peso vivo e dos aspectos produtivos da ave, pois a ave pode perder 16 a 30\% do peso no processo (Bell \& Kuney, 1992) e a utilização de ingredientes de boa qualidade torna-se fundamental para recuperação do peso. Entre esses ingredientes, o gérmen integral de milho, obtido por extração mecânica, apresenta densidade energética similar à do milho, porém com qualidade proteica superior, o que pode reduzir os custos de produção (Brito et al., 2005).

Koelkebeck et al. (2001) avaliaram a inclusão de ingredientes alternativos na dieta de poedeiras comerciais após muda forçada visando diminuir a utilização de milho e aumentar a quantidade de energia e proteína e observaram que dietas com glúten e gérmen integral de milho promoveram retorno mais rápido da produção em comparação a dietas à base de milho e de farelo de soja. Os autores atribuíram os resultados às características próprias dos ingredientes, que proporcionaram elevação nos níveis de aminoácidos digestíveis e de energia da ração. Aves submetidas a esse programa alimentar anteciparam o retorno à produção, proporcionando índices de postura 7,5\% superiores ao do grupo que consumiu apenas milho como fonte principal de energia.

Considerando a importância da utilização de alimentos alternativos na nutrição de poedeiras comerciais, realizou-se este trabalho com o objetivo de avaliar o desempenho e a qualidade dos ovos de poedeiras comerciais no segundo ciclo de produção (78 a 90 semanas de idade) consumindo gérmen integral de milho em substituição ao milho da dieta.

\section{Material e Métodos}

O experimento foi conduzido no período de dezembro de 2003 a maio de 2004 utilizando-se galinhas Lohmann LSL. O procedimento de muda forçada foi realizado com 250 aves da $66^{\mathrm{a}}$ a $74^{\mathrm{a}}$ semana de idade, adotando-se o manejo de muda forçada descrito por Garcia (2004), que consiste inicialmente no descarte das aves de baixo peso e na diminuição gradativa da luminosidade artificial e do arraçoamento até eliminação total, que ocorreu seis dias após o início do procedimento de muda forçada.

As aves foram então mantidas em jejum por 14 dias para redução do peso vivo e finalização completa da postura. Durante esse período, foi fornecida mistura composta de $70 \%$ de calcário calcítico de granulometria fina $(0,5 \mathrm{~mm}) \mathrm{e}$ $30 \%$ de granulometria grossa $(3,0 \mathrm{~mm})$ à vontade às aves. Ao termino do período de jejum, foi fornecida gradativamente às aves ração com baixos níveis de cálcio para readaptação alimentar. No 28ㅡdia, após o jejum, retomou-se a alimentação à vontade e reiniciou-se o programa de iluminação crescente até atingir 17 horas de luz/dia.

As aves atingiram $67,2 \%$ de postura no final da $74 \underline{a}$ semana de idade, oito semanas após o início do programa de muda forçada, momento considerado início do período experimental. Na 75a semana de idade, 192 aves foram uniformizadas pelo peso (peso médio de 1,420 kg e uniformidade de 5\%). A perda de peso média no procedimento de muda forçada foi de $25 \%$. O período de adaptação das aves às dietas experimentais foi da $75^{\mathrm{a}}$ à $77^{\mathrm{a}}$ semana $\mathrm{e}$ o período experimental foi dividido em três ciclos de 28 dias, com 84 dias no total.

As aves foram alojadas em galpão experimental contendo gaiolas de aço galvanizado com espaço de $560 \mathrm{~cm}^{2}$ /ave, com duas aves por compartimento $(0,45 \mathrm{~m}$ de comprimento, 0,25 m de largura e 0,40 m de altura), com $45 \mathrm{~cm}$ de comedouro e bebedouro tipo nipple. No período experimental, foram adotadas 17 horas de luz/dia (natural + artificial), para fornecer 56 lúmens $/ \mathrm{m}^{2}$ durante a iluminação artificial. O arraçoamento e a coleta dos ovos foram realizados duas vezes ao dia.

As dietas experimentais (Tabela 1), isoenergéticas e isonutritivas (menos para os teores de fibra bruta e de gordura), foram formuladas considerando os valores dos ingredientes encontrados nas Tabelas Brasileiras (Rostagno et al., 2005) e a composição nutricional proposta pelo manual técnico da linhagem (Granja Planalto, 2002).

Foram utilizados quatro níveis de substituição do milho por gérmen integral de milho na dieta (0, 25, 50 e 75\%), cada um com quatro repetições de 12 aves. O delineamento utilizado foi o inteiramente casualizado e o gérmen integral de milho utilizado (Tabela 2) nas dietas apresentava no máximo dois meses de fabricação.

Foram avaliados o peso dos ovos, o consumo de ração, a conversão alimentar (kg/kg e kg/dúzia), a porcentagem de postura e a porcentagem de ovos normais, deformados e trincados. Esses dados corresponderam à média da avaliação de todos os ovos produzidos pelas aves durante os 84 dias de experimento. Para análise estatística, os valores de ovos trincados e deformados foram transformados em arco seno.

No final de cada período de produção, cinco ovos de cada repetição (80 ovos no total) foram coletados para avaliação da espessura da casca, gravidade específica, das porcentagens de casca, gema e albúmen, unidade Haugh, índice de pigmentação da gema, conforme escala Roche (Latscha, 1990), índice de gema e sólidos totais dos ovos, da gema e do albúmen. As variáveis analisadas seguiram o proposto por Carbó (1987) e pela Granja Planalto (2002). A 
Tabela 1 - Composição das dietas experimentais

Nível de gérmen integral de milho (\%)

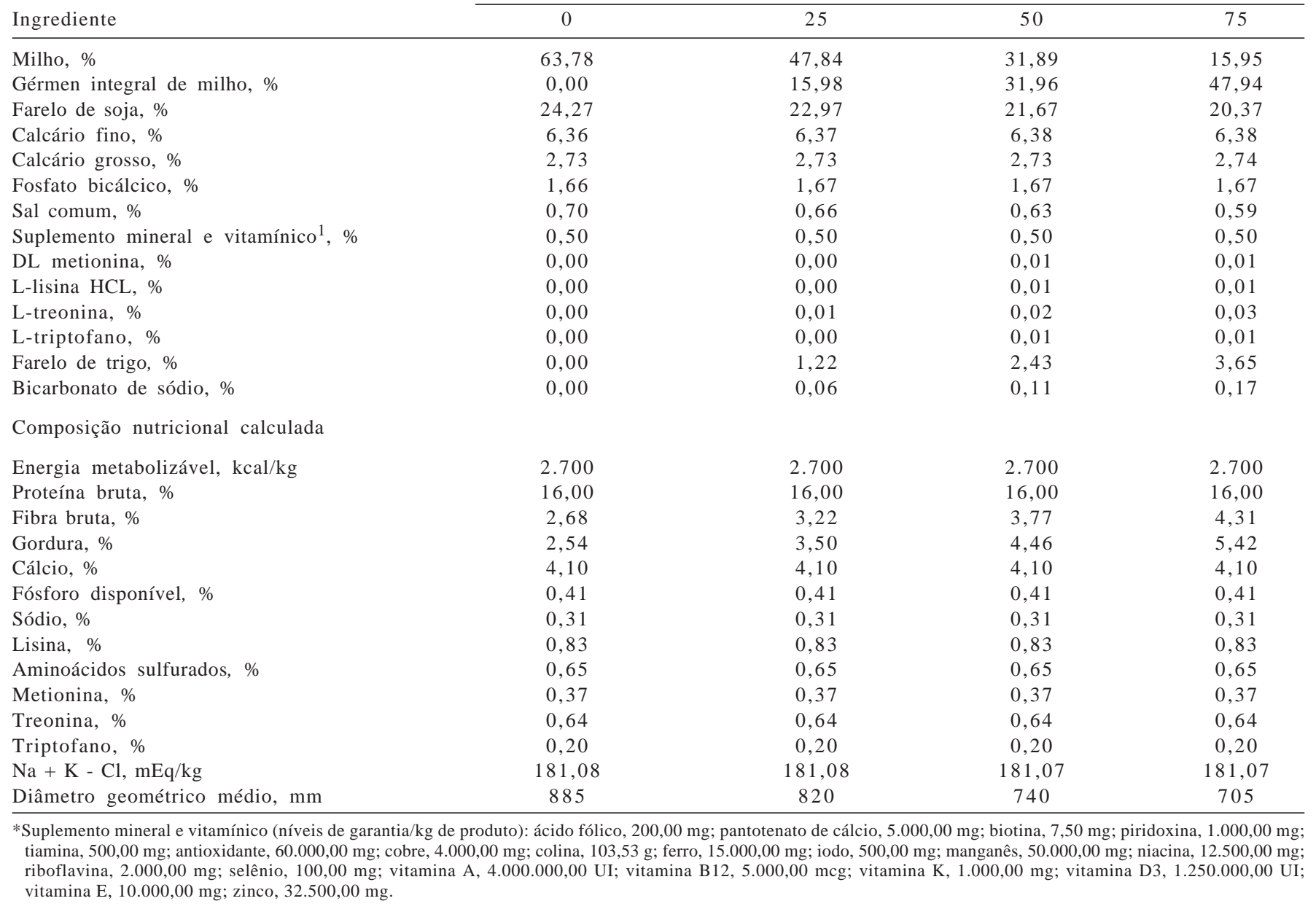

temperatura e a umidade relativa do ar foram obtidas diariamente às $8 \mathrm{~h}$, utilizando-se termo-higrômetro colocado no centro do galpão (Tabela 3).

Foram realizadas análises de variância e de regressão polinomial (5\% de significância) e aplicado o teste Tukey

Tabela 2 - Composição nutricional do gérmen integral de milho

\begin{tabular}{lc}
\hline Nutrientes e energia & Composição \\
\hline Matéria seca, \% matéria natural) \\
Proteína bruta, \% & 90,00 \\
Gordura, \% & 10,88 \\
Cálcio, \% & 9,32 \\
Fósforo disponível, \% & 0,02 \\
Sódio, \% & 0,07 \\
Fibra bruta, \% & 0,025 \\
Lisina, \% & 5,14 \\
Metionina + cistina, \% & 0,41 \\
Metionina, \% & 0,41 \\
Treonina, \% & 0,18 \\
Triptofano, \% & 0,38 \\
Arginina, \% & 0,08 \\
Energia metabolizável, kcal/kg & 0,62 \\
\hline
\end{tabular}

Fonte: Brito et al. (2005) para comparação das médias, adotando-se o programa computacional SAEG (UFV, 2000) para as análises estatísticas.

\section{Resultados e Discussão}

Na análise do desempenho e da porcentagem de postura (Tabela 4), observou-se efeito quadrático $(\hat{Y}=0,227$ $0,000632 \mathrm{X}+0,000000724 \mathrm{X}^{2}, \mathrm{P}=0,05$ ) dos níveis de gérmen integral de milho sobre a porcentagem de ovos deformados (Figura 1). A derivação dessa equação resultou no ponto de máxima deformidade nos níveis de 43,6\% e 27,87\% de substituição do milho por gérmen integral de milho na dieta. Não foram observadas diferenças $(\mathrm{P}>0,05)$ para nenhuma outra característica de desempenho analisada. Os resultados da avaliação do desempenho e da porcentagem de postura indicam não existir restrições à substituição de até $75 \%$ do milho por gérmen integral de milho na dieta de poedeiras comerciais após a 76aㅡ semana de idade. 
Tabela 3 - Médias de temperatura ambiente e da umidade relativa obtidas durante o período experimental

\begin{tabular}{|c|c|c|c|c|c|c|}
\hline \multirow[t]{2}{*}{ Ciclos de produção } & \multicolumn{3}{|c|}{ Temperatura $\left({ }^{\circ} \mathrm{C}\right)$} & \multicolumn{3}{|c|}{ Umidade relativa (\%) } \\
\hline & Máxima & Mínima & Média & Máxima & Mínima & Média \\
\hline 1 & 31,2 & 22,4 & 26,8 & 87,2 & 63,5 & 75,4 \\
\hline 2 & 32,3 & 24,5 & 28,4 & 88,3 & 64,8 & 76,6 \\
\hline 3 & 31,9 & 23,1 & 27,5 & 86,2 & 62,2 & 74,2 \\
\hline Média & 31,8 & 23,3 & 27,6 & 87,2 & 63,5 & 75,4 \\
\hline
\end{tabular}

Tabela 4 - Desempenho de poedeiras comerciais de 78 a 90 semanas de idade (pós-muda) alimentadas com rações contendo gérmen integral de milho em substituição ao milho em grão

\begin{tabular}{lccccc}
\hline & \multicolumn{3}{c}{ Nível de gérmen integral de milho (\%) } & Valor de P \\
\cline { 2 - 5 } & 0 & 25 & 50 & 75 & \\
\hline Consumo de ração, g/dia & 107,6 & 110,0 & 105,7 & 110,4 & 0,13 \\
Conversão alimentar, kg/kg & 2,09 & 1,99 & 2,05 & 1,93 & 0,12 \\
Conversão alimentar, kg/dz & 1,60 & 1,56 & 1,59 & 1,53 & 4,63 \\
Postura, \% & 80,8 & 84,8 & 84,0 & 86,4 & 0,37 \\
\hline
\end{tabular}

$\mathrm{CV}=$ coeficiente de variação.

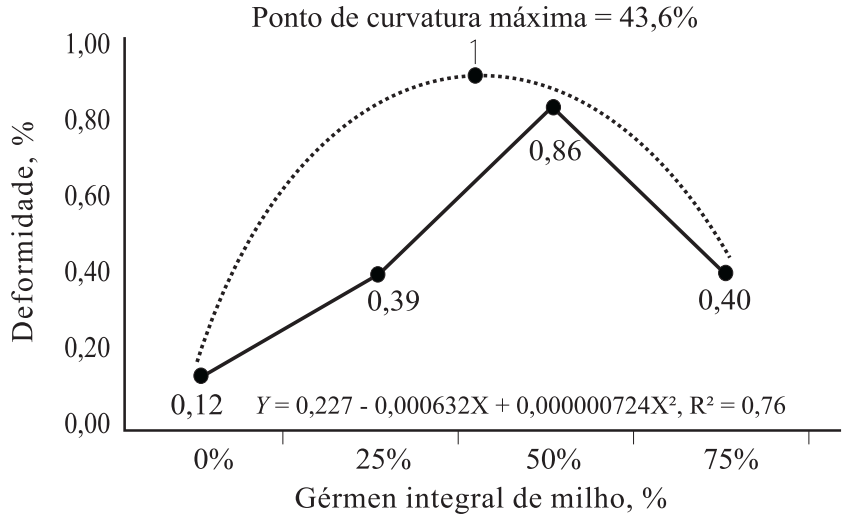

Figura 1 - Porcentagem de ovos deformados (Defor, \%) poedeiras comerciais de 78 a 90 semanas de idade que consumiram diferentes níveis de gérmen integral de milho (GIM) em substituição ao milho grão da ração.

Como o número de informações sobre o gérmen integral de milho é reduzido, é possível comparar os resultados deste estudo aos obtidos com poedeiras comerciais alimentadas com dietas com milho de alto conteúdo de óleo na dieta, obtido pelo aumento na proporção de gérmen. Embora não tenham sido observadas diferenças $(\mathrm{P}>0,05)$ entre os níveis de gérmen integral de milho, os resultados da porcentagem de postura e do peso dos ovos (Tabela 4) assemelham-se aos obtidos por Harms et al. (2004), que avaliaram os efeitos da inclusão de 0,3 e $6 \%$ de milho alto óleo nas dietas de poedeiras comerciais após a 40 a semana de idade e observaram aumento de 88,6 para 90,3\% na produtividade e 59,7 para 61,9 g no peso dos ovos em aves alimentadas com rações contendo 6\% de milho alto óleo. Existe relação entre o aumento do conteúdo de ácidos graxos na dieta, principalmente os poliinsaturados (PUFA), com o aumento do peso e do volume da gema ou do índice de gema dos ovos (Collins et al., 1997; Du et al., 1999; Gao \& Charter, 2000; Lee et al., 2001; Yang et al., 2002; Watkins et al., 2003).

De acordo com Grobas et al. (2001), a inclusão de óleos vegetais ou de alimentos de origem vegetal ricos em óleo (ex.: gérmen integral de milho) proporciona aumento no peso da gema $(3,0 \%)$ e na porcentagem de gordura dos ovos (3,5\%). Considerando os dados de qualidade interna dos ovos (Tabela 5) obtidos neste estudo, houve efeito $(\mathrm{P}<0,05)$ linear positivo $(\mathrm{P}<0,05)$ sobre a unidade Haugh (Figura 2$) \mathrm{e}$ efeito negativo sobre os índices de gema (Figura 3) e de pigmentação da gema (Figura 4). Não ocorreu diferença $(\mathrm{P}>0,05)$ entre os níveis de gérmen integral de milho para as outras variáveis de qualidade interna dos ovos.

A redução do percentual de gema e o aumento da porcentagem de albúmen são, na maioria das vezes, responsáveis pela variação da unidade Haugh e do índice de gema, pois ambos são resultantes das relações entre altura e peso da gema e do albúmen (Kim et al., 2005), o que pode constituir problema para agroindústrias beneficiadoras de ovos (Anderson et al., 2004). A baixa pigmentação ocasionada pelo aumento do nível de gérmen integral de milho na dieta pode ser explicada pela menor quantidade de xantofila no gérmen do milho. Moros et al. (2002) avaliaram 
Tabela 5 - Características dos ovos de poedeiras comerciais de 78 a 90 semanas de idade (pós-muda) alimentadas com rações contendo gérmen integral de milho em substituição ao milho em grão

\begin{tabular}{|c|c|c|c|c|c|c|c|c|}
\hline & \multicolumn{4}{|c|}{ Nível de gérmen integral de milho (\%) } & \multirow[t]{2}{*}{ Valor de $\mathrm{P}$} & \multirow[t]{2}{*}{$\mathrm{CV}$} & \multirow[t]{2}{*}{ Efeito } & \multirow[t]{2}{*}{$\mathrm{R}^{2}$} \\
\hline & 0 & 25 & 50 & 75 & & & & \\
\hline Ovos normais, \% & 79,6 & 82,7 & 77,9 & 84,5 & 0,11 & 4,73 & ns & - \\
\hline Ovos trincados, \% & 1,07 & 1,37 & 1,25 & 1,55 & $>0,500$ & 5,55 & ns & - \\
\hline Ovos deformados, \% & 0,12 & 0,39 & 0,86 & 0,40 & 0,05 & 3,16 & $\mathrm{Q}$ & 0,76 \\
\hline Gema, \% & 25,48 & 25,85 & 25,76 & 24,87 & 0,385 & 3,30 & ns & - \\
\hline Índice de gema, $\mathrm{cm} / \mathrm{cm}$ & 0,391 & 0,387 & 0,381 & 0,375 & 0,002 & 1,61 & $\mathrm{~L}$ & 0,99 \\
\hline Índice de pigmentação da gema & 6,57 & 5,83 & 5,35 & 4,82 & 0,001 & 3,77 & $\mathrm{~L}$ & 0,99 \\
\hline Sólidos totais da gema, \% & 52,05 & 51,64 & 52,47 & 51,58 & 0,390 & 1,51 & ns & - \\
\hline Sólidos totais do albúmen, \% & 11,86 & 11,78 & 11,26 & 11,47 & 0,066 & 2,73 & ns & - \\
\hline Sólidos totais do ovo, \% & 23,76 & 24,23 & 23,95 & 24,06 & $>0,500$ & 1,99 & ns & - \\
\hline Gravidade específica & 1,0877 & 1,0866 & 1,0846 & 1,0853 & 0,003 & 0,11 & $\mathrm{~L}$ & 0,74 \\
\hline
\end{tabular}

$\mathrm{CV}$ = coeficiente de variação; ns = não-significativo; $\mathrm{Q}=$ quadrático; $\mathrm{L}=$ linear.

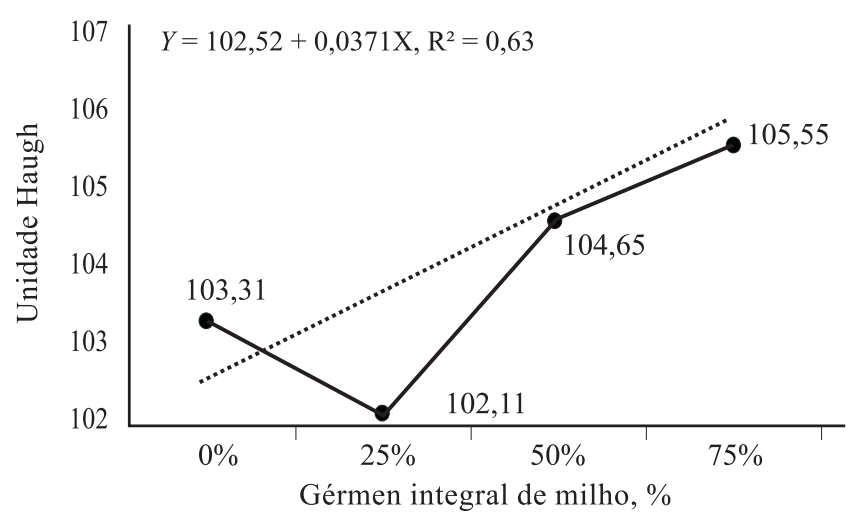

Figura 2 - Unidade Haugh obtida em ovos de poedeiras comerciais de 78 a 90 semanas de idade alimentadas com diferentes níveis de gérmen intergal de milho (GIM) em substituição ao milho grão da ração.

o teor de xantofilas do milho e de seus subprodutos por cromatografia líquida de alta precisão e observaram valor médio de xantofila de 20,09 mg/g para o milho amarelo e de $0,12 \mathrm{mg} / \mathrm{g}$ para o milho opaco. Os autores também relataram que a pigmentação difere entre as regiões do grão de milho. A parte amilácea ou o endocarpo do grão de onde se extrai o farelo de glúten do milho é a porção com maiores teores de xantofilas (145,91 mg/g de milho), enquanto a parte correspondente ao gérmen integral de milho possui baixa fração desse pigmento (1,88 mg/g de milho).

A formação da gema do ovo é uma importante forma de eliminação de resíduos lipossolúveis do organismo das poedeiras. As xantofilas são lipossolúveis e, quando depositadas na gema, proporcionam coloração característica, que pode ser maior ou menor, dependendo da quantidade de pigmentantes ingeridos (Silva et al., 2000).
Na média, os valores de qualidade de casca dos ovos obtidos da $78^{\underline{a}}$ a 90 a semana de idade diferiram $(\mathrm{P}<0,05)$ entre os níveis de gérmen integral de milho utilizados na dieta. Houve efeito linear negativo $(\mathrm{P}<0,05)$ do nível de gérmen integral de milho sobre a gravidade específica ( $\hat{Y}=1,087$ $\left.0,000036 X, R^{2}=0,74\right)$ e efeito quadrático sobre a espessura ( $\left.\hat{Y}=39,34-0,086 X+0,00086 X^{2}, R^{2}=0,86\right)$ e a porcentagem de casca $\left(\hat{\mathrm{Y}}=9,51-0,0225 \mathrm{X}+0,000197 \mathrm{X}^{2}, \mathrm{R}^{2}=0,96\right)$ (Figuras 5, 6 e 7, respectivamente). As derivações das duas últimas equações resultaram nos pontos de mínima de $50 \%$ e $57,1 \%$ de substituição do milho, ou seja, 31,96\% e 36,5\% de gérmen integral de milho na dieta, respectivamente.

A pior qualidade da casca de ovos de poedeiras comerciais após a $78^{\mathrm{a}}$ semana de idade consumindo altos níveis de gérmen integral de milho pode estar relacionada ao aumento no teor de gordura das dietas (Tabela 1). O maior conteúdo de matéria graxa no intestino pode ocasionar a formação de sabões, que incluem nutrientes, principalmente cálcio, (Cleaver et al., 1986; Bohnsack et al., 2001), prejudicando a qualidade da casca e a mineralização óssea das aves (Riczu et al., 2004; Kim et al., 2005; Mazzuco \& Hester, 2005).

É possível fazer um paralelo entre os resultados obtidos com o gérmen integral de milho e a qualidade de casca, considerando alguns trabalhos realizados com poedeiras comerciais alimentadas com milho de alto conteúdo de óleo na dieta, uma vez que o aumento do conteúdo energético de óleo é obtido pelo aumento da fração do gérmen no grão. Lee et al. (2001), por exemplo, avaliaram o teor nutricional do milho alto óleo para poedeiras comerciais e não observaram diferenças na espessura $(\mathrm{mm})$ e densidade de casca $\left(\mathrm{mg} / \mathrm{cm}^{2}\right)$ em comparação ao uso do milho comum. De 

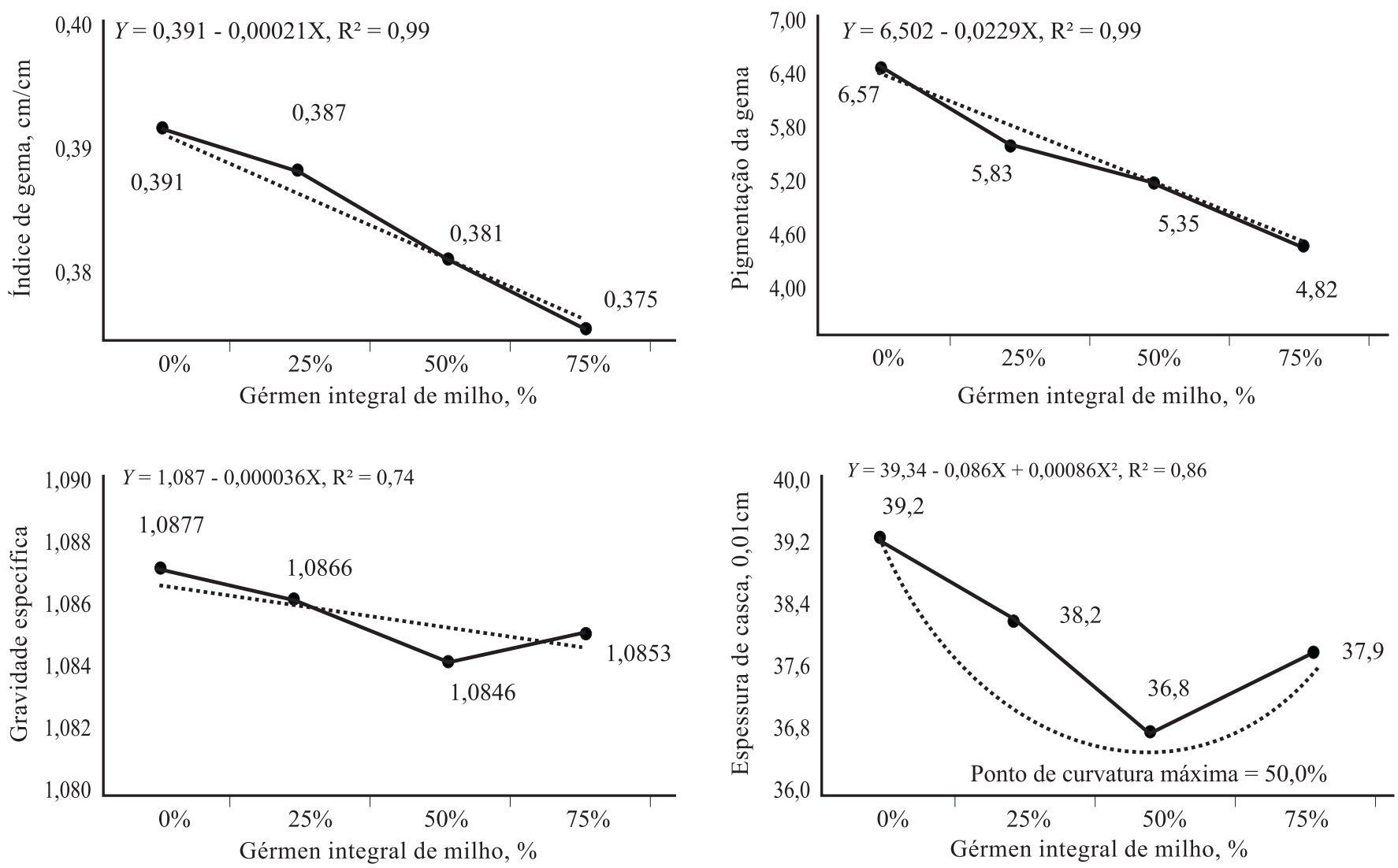

Figura 3 - Características dos ovos de poedeiras comerciais de 78 a 90 semanas de idade alimentadas com rações contendo gérmen integral de milho em substituição ao milho grão.

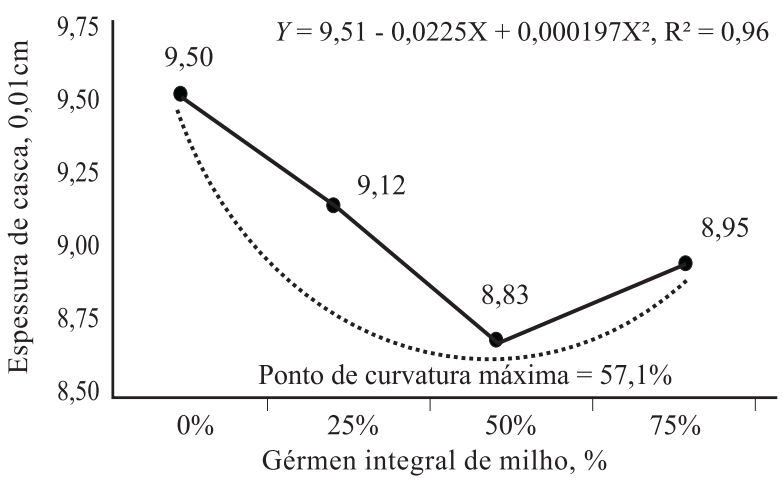

Figura 4 - Porcentagem de casca (Casca, \%) em ovos de poedeiras comerciais de 78 a 90 semanas de idade consumindo rações contendo gérmen integral de milho (GIM) em substituição ao milho grão.

acordo com esses autores, a única diferença significativa $(\mathrm{P}<0,05)$ foi na eficiência econômica, pois o milho com alto conteúdo de óleo reduziu o preço das dietas e possibilitou melhor equilíbrio do perfil de aminoácidos do milho com alto teor de óleo em comparação ao milho comum, permitindo reduzir o nível de farelo de soja e o preço da dieta.

\section{Conclusões}

A utilização de gérmen integral de milho em níveis de até $25 \%$ de substituição ao milho em grão permite manter o desempenho de poedeiras após muda forçada. Níveis superiores podem reduzir a pigmentação da gema e a qualidade da casca dos ovos.

\section{Agradecimentos}

À GEM Alimentos, à Nutron Alimentos e ao CNPq, pelo apoio financeiro.

\section{Literatura Citada}

ANDERSON, K.E.; DAVIS, G.S.; JENKINS, P.K. et al. Effects of bird age, density, and molt on behavioral profiles of two commercial layer strains in cages. Poultry Science, v.83, n.1, p.15-23, 2004.

BELL, D.; KUNEY, D.R. Effect of fasting and post-fast diets on performance in molted flocks. Journal of Applied Poultry Research, v.1, n.2, p.200-206, 1992.

BOHNSACK, C.R.; HARMS, R.H.; MERKEL, W.D. et al. Performance of commercial layers when fed diets with four levels of corn oil or poultry fat. Journal of Applied Poultry Research, v.11, n.1, p.46-68, 2001. 
BRITO, A.B.; STRINGHINI, J.H.; CRUZ, C.P. et al. Avaliação nutricional do gérmen integral de milho para aves. Ciência Animal Brasileira, v.6, n.1, p.19-26, 2005.

CARBÓ, C.B. El huevo comercial: estructura, composición, calidad y manejo. In: CARBÓ, C.B. (Ed.) La gallina ponedora. 1.ed. Madrid: Mundi-Prensa, 1987. cap.9, p.379-424.

CLEAVER, W.T.; CHRISTENSEN, V.L.; ORT, J.F. Physiological characteristics of a molt and second cycle of egg laying in turkey breeder hens. Poultry Science, v.65, n.12, p.2335-2342, 1986.

COLLINS, V.P. Pearl millet in layer diets enhances egg yolk n-3 fatty acids. Poultry Science, v.76, n.2, p.326-330, 1997.

DU, M. Effect of dietary conjugated linoleic acid on the composition of egg yolk lipids. Poultry Science, v.78, n.11, p.1639-1645, 1999.

GAO, Y.C.; CHARTER, E.A. Nutritionally important fatty acids in hen egg yolks from different sources. Poultry Science, v.79, n.6, p.921-924, 2000.

GARCIA, E.A. Muda forçada em poedeiras comerciais e codornas. In: CONFERÊNCIA APINCO DE CIÊNCIA E TECNOLOGIA AVÍCOLAS. 2004, Santos. Anais... Campinas: Fundação APINCO de Ciência e Tecnologia Avícolas, 2004. p.45-62.

GRANJA PLANALTO. Manual de criação e manejo Lohman LSL. Controle de produção avícola. Uberlândia: Granja Planalto, 2002. 26p.

GROBAS, S.; MENDEZ, J.; LAZARO, R. et al. Influence of source and percentage of fat added to diet on performance and fatty acid composition of egg yolks of two strains of laying hens. Poultry Science, v.80, n.8 p.1171-1174, 2001.

HARMS, R.H.; RUSSELL, G.B.; BOHNSACK, C.R. et al. The effect of corn oil reduction in the diet on laying hen performance. Revista Brasileira de Ciência Avícola, v.6, n.3, p.183-186, 2004.

KIM, W.K.; DONALSON, L.M.; HERRERA, P. et al. Comparisons of molting diets on skeletal quality and eggshell parameters in hens at the end of the second egg-laying cycle. Poultry Science, v.84, n.4, p.522-527, 2005.
KOELKEBECK, K.W.; PARSONS, C.M.; DOUGLAS, M.W. et al. Early postmolt performance of laying hens fed a low-protein corn molt diet supplemented with spent hen meal. Poultry Science, v.80, n.3, p.353-357, 2001.

LATSCHA, E.C. Egg yolk pigmentation with carophyll. Basel: Roche, 1990. 35p.

LEE, B.D.; KIM, D.J.; LEE, S.J. Nutritive and economic values of high oil corn in layer diet. Poultry Science, v.80, n.8, p.1527-1534, 2001.

MAZZUCO, H.; HESTER, P.Y. The effect of an induced molt and a second cycle of lay on skeletal integrity of white leghorns. Poultry Science, v.84, n.5, p.771-781, 2005.

MOROS, E.E.; DARNOKO, D.; CHERYAN, M. et al. Analysis of xanthophylls in corn by HPLC. Journal of Agriculture and Food Chemistry, v.50, n.21, p.5787-5790, 2002.

RICZU, C.M.; SAUNDERS-BLADES, J.L.; YNGVESSON, A.K. et al. End-of-cycle bone quality in white- and brown-egg laying hens. Poultry Science, v.83, n.3, p.375-383, 2004.

ROSTAGNO, H.S. Tabelas brasileiras para aves e suínos Composição de alimentos e exigências nutricionais. 2.ed. Viçosa, MG: Universidade Federal de Viçosa, 2005. 186p.

SILVA, J.H.V.; ALBINO, L.F.T.; GOIDÓI, M.J.S. Efeito do extrato de urucum na pigmentação da gema dos ovos. Revista Brasileira de Zootecnia, v.29, n.5, p.1435-1439, 2000.

UNIVERSIDADE FEDERAL DE VIÇOSA - UFV. Sistema de análises estatísticas e genéticas - SAEG. Versão 7.1. Viçosa, MG: Fundação Arthur Bernardes, 2000. 150p. [Manual do usuário].

WATKINS, B.A.; FENG, S.; STROM,A.K. et al. Conjugated linoleic acids alter the fatty acid composition and physical properties of egg yolk and albumen. Journal of Agricultural Food Chemistry, v.51, n.23, p.6870-6876, 2003.

YANG, L.; HUANG, Y.; JAMES, A.E. et al. Differential incorporation of conjugated linoleic acid isomers into egg yolk lipids. Journal of Agricultural Food Chemistry, v.50, n.17, p.4941-4946, 2002. 